\title{
One-Step Physical Synthesis of Composite Thin Film
}

\author{
Seishi Abe \\ Research Institute for Electromagnetic Materials \\ Japan
}

\section{Introduction}

Quantum-dot solar cells have attracted much attention because of their potential to increase conversion efficiency of solar photo conversion up to almost $66 \%$ by utilizing hot photogenerated carriers to produce higher photovoltages or higer photocurrents (Nozik, 2002). Specifically, the optical-absorption edge of a semiconductor nanocrystal is often shifted due to the quantum-size effect. The optical band gap can then be tuned to the effective energy region for absorbing maximum intensity of the solar radiation spectrum (Landsberg et al., 1993; Kolodinski et al., 1993). Furthermore, quantum dots produce multiple electron-hole pairs per -photon through impact ionization, whereas bulk semiconductor produces one electron-hole pair per -photon.

Wide gap semiconductor sensitized by semiconductor nanocrystal is candidate material for such use. The wide gap materials such as $\mathrm{TiO}_{2}$ can only absorb the ultraviolet part of the solar radiation spectrum. Hence, the semiconductor nanocrystal supports absorbing visible (vis)- and near-infrared (NIR) -light. Up to now, various nanocrystalline materials [InP (Zaban et al., 1998), CdSe (Liu \& Kamat, 1994), CdS (Weller, 1991; Zhu et al., 2010), PbS (Hoyer \& Könenkamp, 1995), and Ge (Chatterjee et al., 2006)] have been investigated, for instance, as the sensitizer for $\mathrm{TiO}_{2}$. Alternatively, a wide-gap semiconductor $\mathrm{ZnO}$ is also investigated, since the band gap and the energetic position of the valence band maximum and conduction band minimum of $\mathrm{ZnO}$ are very close to that of $\mathrm{TiO}_{2}$ (Yang et al., 2009). Most of these composite materials were synthesized through chemical techniques, however, physical deposition, such as sputtering, is also useful. In addition, package synthesis of the composite thin film is favorable for low cost product of solar cell.

In this chapter, $\mathrm{Ge} / \mathrm{TiO}_{2}$ and $\mathrm{PbSe} / \mathrm{ZnSe}$ composite thin film are presented, and they were prepared through rf sputtering and hot wall deposition (HWD), with multiple resources for simultaneous deposition. The package synthesis needs the specific material design for each of the preparation techniques. In the rf sputtering, the substances for nanocrystal and matrix are appropriately selected according to the difference in heat of formation (Ohnuma et al., 1996). Specifically, Ge nanocrystals are thermodynamically stable in a $\mathrm{TiO}_{2}$ matrix, since $\mathrm{Ti}$ is oxidized more prominently than Ge along the fact that the heat of formation of $\mathrm{GeO}_{2}$ is greater than those of $\mathrm{TiO}_{2}$ (Kubachevski \& Alcock, 1979). Larger difference in the heat of formation [e.g., Ge/Al-O (Abe et al., 2008a)] can provide thermodynamically more stable nanocrystal. Hence, the crystalline Ge was homogeneously embedded in amorphous $\mathrm{Al}$ oxide matrix, and evaluated unevenness of the granule size was ranged from 2 to $3 \mathrm{~nm}$, according to high resolution electron microscopy (HREM). In the HWD, on the other hand, 
the substances for nanocrystal and matrix are also selected following thermodynamic insolubility. The HWD technique, which is a kind of thermal evaporation, causes unintentional increase of the substrate-temperature due to the thermal irradiation. Hence, simultaneous HWD evaporation from multiple resources often produces solid solution [e.g., $\mathrm{Pb}_{1-x} \mathrm{Ca}_{x} \mathrm{~S}$ (Abe \& Masumoto, 1999)]. Hence, package synthesis of the composite thin film needs insolubility material system. The bulk PbSe-ZnSe system, for instance, is found to phase-separate at thermal equilibrium state (Oleinik et al., 1982). It is therefore expected that PbSe nanocrystals phase-separate from the ZnSe matrix in spite of the simultaneous evaporation from PbSe- and ZnSe-resource.

Accordingly, the two thermodynamic material-designs, heat of formation for rf sputtering and insolubility system for HWD, are employed here for package synthesis of composite thin film. This chapter focuses on one-step physical synthesis of $\mathrm{Ge} / \mathrm{TiO}_{2}$ composite thin films by rf sputtering and PbSe/ZnSe composite thin films by HWD, as candidate materials for quantum dot solar cell.

\section{2. $\mathrm{Ge} / \mathrm{TiO}_{2}$ composite thin films}

$\mathrm{TiO}_{2}$ mainly has crystal structures of rutile, anatase and brookite. It is believed that the anatase structure is favorable for the matrix, since carrier mobility and photoconductivity in the anatase structure exceed those in the rutile structure (Tang et al., 1994). It is difficult to forecast how the crystal structure of the $\mathrm{TiO}_{2}$ matrix will be formed in such composite films. In fact, $\mathrm{Ge} / \mathrm{TiO}_{2}$ films prepared by rf sputtering employing a mixture target of $\mathrm{TiO}_{2}$ and $\mathrm{Ge}$ powder hitherto contained anatase- and rutile -structure almost equally (Chatterjee, 2008). Hence, it is investigated here that the composition of $\mathrm{Ge} / \mathrm{TiO}_{2}$ films is thoroughly varied for preparing the anatase structure of the $\mathrm{TiO}_{2}$ matrix while retaining vis-NIR absorption of Ge quantum dots.

\subsection{Anatase-dominant matrix in $\mathrm{Ge} / \mathrm{TiO}_{2}$ thin films prepared by rf sputtering}

The present study employed a new method of preparing $\mathrm{Ge} / \mathrm{TiO}_{2}$ films using a composite target of a Ge chip set on a $\mathrm{TiO}_{2}$ disk, and their composition has been thoroughly changed. Figure 2-1(a) depicts the X-ray diffraction (XRD) pattern of $\mathrm{Ge} / \mathrm{TiO}_{2}$ thin films as a function of Ge concentration. In this case, the additional oxygen ratio in argon is kept constant at $0 \%$. Labels A through E indicate Ge concentrations of 0, 1.9, 6.8, 8.1, and 21at.\% by adopting 0, 1, 2, 3 , and 21 Ge chips. XRD patterns first exhibited an amorphous state in as-deposited films, and several diffraction peaks began to appear at $723 \mathrm{~K}$ when the post-annealing temperature was raised from 673 to $873 \mathrm{~K}$ in $50 \mathrm{~K}$ steps. These peaks were assigned to $\mathrm{TiO}_{2}$, and the films were therefore crystallized at around $723 \mathrm{~K}$ (not shown here). A single-phase rutile structure is observed at a Ge concentration of 0at.\% in the figure, corresponding to simple preparation of pure $\mathrm{TiO}_{2}$ thin film. In our preliminary experiment for preparing the $\mathrm{TiO}_{2}$ thin films, a singlephase anatase structure was obtained for oxygen ratios exceeding $0.5 \%$ and the successive post-annealing treatment. An insufficient oxygen ratio thus seems to cause formation of the rutile structure. Next, with a slight addition of Ge in the pattern of B, distinct diffraction peaks of anatase structure begin to appear, and the (101) Bragg reflection is dominant. Further addition of $\mathrm{Ge}$, as seen in patterns $\mathrm{C}$ and $\mathrm{D}$, produces different behavior in orientation, increasing the peak intensity at (004) reflection of the anatase structure. Finally, dominant, broad peaks of Ge can be observed with excess Ge addition in pattern E. The average size of the Ge nanogranules is estimated to be about $6.6 \mathrm{~nm}$ based on the full-width at half maximum of the XRD peak employing Scherrer's equation (Scherrer, 1918). According to the variation of Ge concentration, the anatase structure is favorably promoted in patterns B, C, and D. 

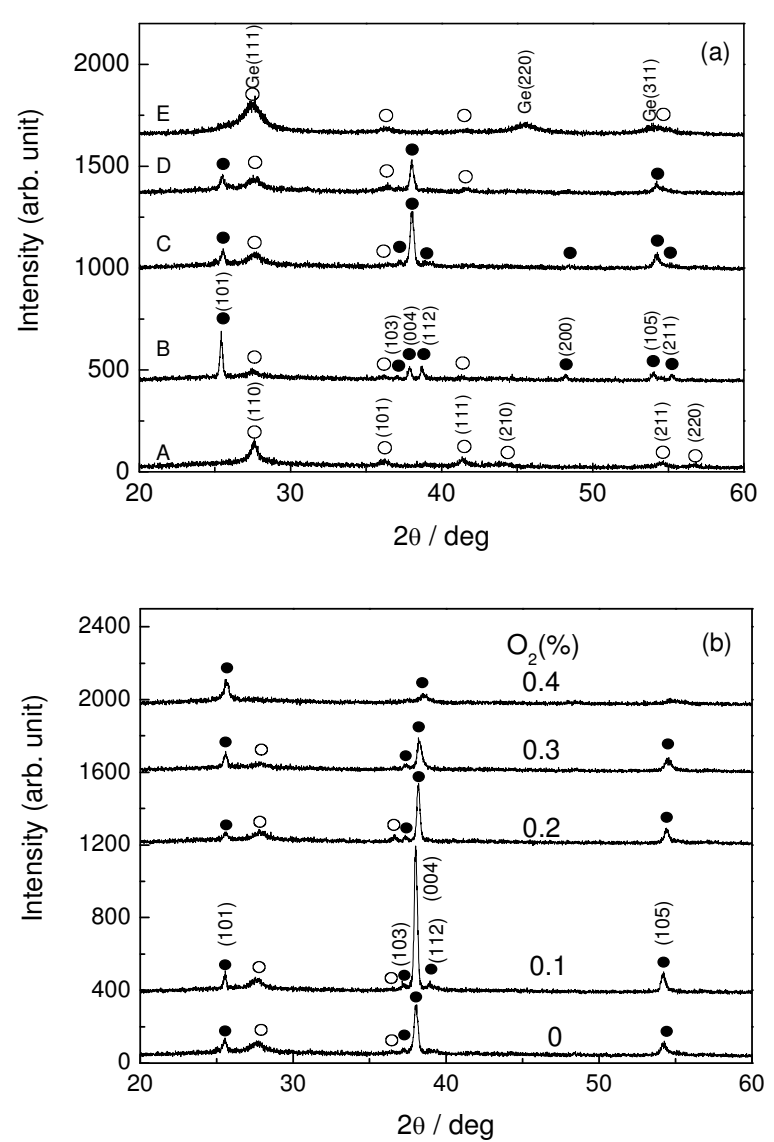

Fig. 2.1. (a) XRD patterns of $\mathrm{Ge} / \mathrm{TiO}_{2}$ composite films versus $\mathrm{Ge}$ concentrations. $(\bullet)$ indicates anatase structure, and $(\circ)$, rutile structure. (b) Same patterns versus additional oxygen ratio in argon. $(\bullet)$ indicates anatase structure, and $(\circ)$, rutile structure (b) (after Abe et al., 2008b).

Figure 2-1(b) depicts the XRD pattern of $\mathrm{Ge} / \mathrm{TiO}_{2}$ thin films as a function of the additional oxygen ratio in argon. In this case, the oxygen ratio is varied from 0 to $0.4 \%$, and the number of Ge chips is kept constant at 2. When the ratio is increased to $0.1 \%$, the (004) Bragg reflection becomes more prominent as seen in the figure. A further increase of the oxygen ratio then indicates weakness. An anatase-dominant structure with strong intensity at (004) reflection is thus observed at an oxygen ratio of $0.1 \%$. We cannot observe an XRD peak of Ge in the pattern within the precision of our experiment technique, possibly due to the relatively low Ge concentration of 5.8at.\%. This c-axis growth behavior in an anatase-dominant structure seems to be unique even though the composite film is deposited on a glass substrate. Thus, the crystal structure of $\mathrm{TiO}_{2}$ matrix is found to be changed with respect to the Ge number and the oxygen ratio as illustrated in Figs. 2-1(a) and 2-1(b). 


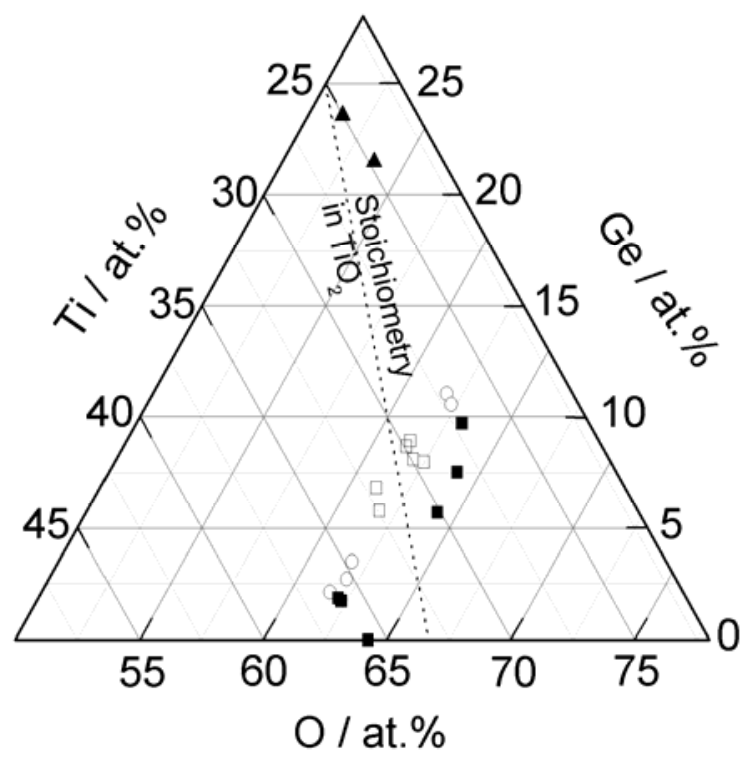

Fig. 2.2. Compositional plane of crystal structure of $\mathrm{TiO}_{2}$ matrix in $\mathrm{Ge} / \mathrm{TiO}_{2}$ composite films. $(\circ)$ indicates anatase structure, and $(\mathbf{\Delta})$, rutile structure. $(\mathbf{})$ indicates coexistence of anatase and rutile structure. In particular, $(\square)$ indicates anatase-dominant structure with strong intensity at (004) reflection (after Abe et al., 2008b).

The relation between the analyzed composition of the films and the structure of $\mathrm{TiO}_{2}$ matrix is summarized in Fig. 2-2 based on these results. The stoichiometric composition of $\mathrm{TiO}_{2}$ is also plotted as a dotted line. The single phase of anatase structure ( $\circ$ ) can be seen in the figure, but its visible absorption is quite weak. These films therefore do not achieve the present objective. A mixed phase containing anatase- and rutile -structure ( $\mathbf{a})$ appears in a wide range of $\mathrm{Ge}$ concentrations. In particular, an anatase-dominant structure with strong (004) reflection ( $\square$ ) is found at a Ge concentration of 6 to 9at.\% near the stoichiometric composition of $\mathrm{TiO}_{2}$. The optical absorption will be discussed using the following figure. The rutile structure $(\mathbf{\Delta})$ is observed at a relatively high Ge concentration range. In these films, diffraction peaks of Ge nanogranules were observed at the same time [Fig. 2-1(a)]. Accordingly, the anatase-dominant structure with strong (004) reflection ( $\square$ ) is regarded to be the most optimized structure in the present study. As a further optimization, total gas pressure was varied from $2 \mathrm{mTorr}$ to $10 \mathrm{mTorr}$ in the optimized composition range. The (004) Bragg reflection was maximized at a gas pressure of 6mTorr; however, a slight amount of rutile structure still remained.

In the above sections, the structural optimization of the $\mathrm{TiO}_{2}$ matrix in the $\mathrm{Ge} / \mathrm{TiO}_{2}$ composite films was focused. Next, we shall investigate the optical properties. Figure 2-3 depicts the typical optical absorption spectra of $\mathrm{Ge} / \mathrm{TiO}_{2}$ thin films thus optimized. For comparison, the spectrum of $\mathrm{TiO}_{2}$ thin film is also presented in the figure. Ge has an indirect band-gap structure (Macfarlane et al., 1957), and the square root of absorbance is employed. As seen in the figure, the onset absorption can be confirmed at around $1.0 \mathrm{eV}$ in contrast to UV absorption of $\mathrm{TiO}_{2}$ thin films due to its energy band gap of $3.2 \mathrm{eV}$ in the anatase 
structure. They can favorably cover the desirable energy region for high conversion efficiency (Loferski, 1956). Therefore, it should be pointed out that valuable characteristics of vis-NIR absorption and anatase-dominant structure of $\mathrm{TiO}_{2}$ matrix are simultaneously retained in the $\mathrm{Ge} / \mathrm{TiO}_{2}$ composite thin films as a result of compositional optimization. Ge addition is first motivated to demonstrate the quantum size effect, then, it is worthy of note that its addition also effectively controls the crystal structure of the $\mathrm{TiO}_{2}$ matrix. Consequently, a single phase of anatase structure cannot be obtained. However, extensive progress can be made in structural formation of the $\mathrm{TiO}_{2}$ matrix as a result of exhaustive compositional investigation. Based on these results, $\mathrm{Ge} / \mathrm{TiO}_{2}$ thin films having an anatasedominant structure of $\mathrm{TiO}_{2}$ matrix and vis-NIR absorption should also be regarded as candidate materials for quantum dot solar cell.

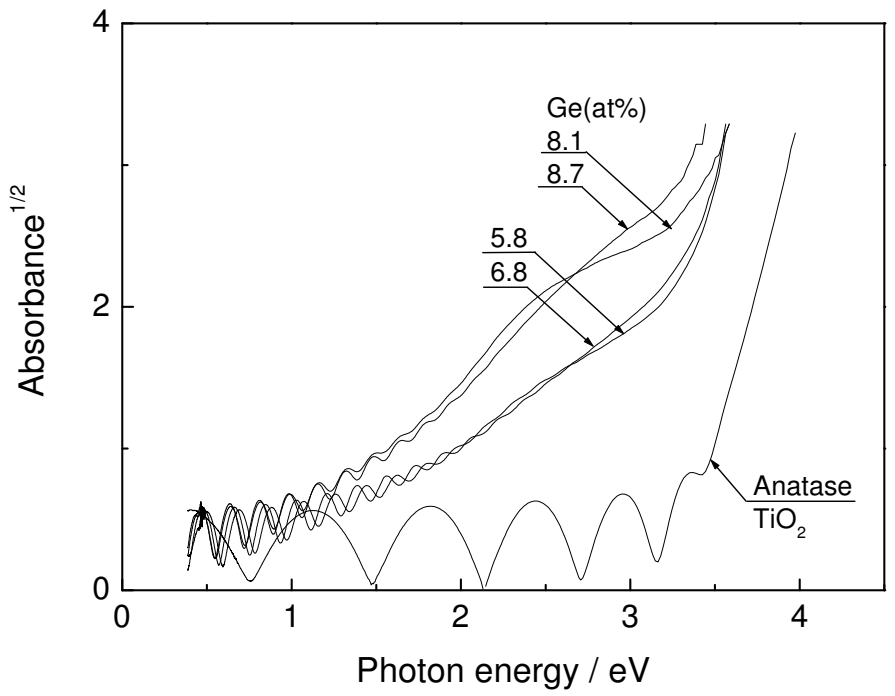

Fig. 2.3. Typical optical absorption spectra of $\mathrm{Ge} / \mathrm{TiO}_{2}$ composite films with anatasedominant structure of $\mathrm{TiO}_{2}$ matrix (after Abe et al., 2008b).

\subsection{Solubility range and energy band gap of powder-synthesized $\mathrm{Ti}_{1-x} \mathrm{Ge}_{x} \mathrm{O}_{2}$ solid solution}

As a reason for the vis-NIR absorption, the quantum size effect probably appeared owing to the presence of Ge nanogranules. However, a ternary solid solution of $\mathrm{Ti}_{1-x} \mathrm{Ge}_{x} \mathrm{O}_{2}$ is possibly formed as a matrix during the postannealing, and the solubility range of Ge and its energy band gap are hitherto unclear. Therefore, the reason for the vis-NIR absorption requires further investigation. To demonstrate whether the matrix exhibits the vis-NIR absorption, powder synthesis of a ternary $\mathrm{Ti}_{1-x} \mathrm{Ge}_{x} \mathrm{O}_{2}$ solid solution is carried out. Specifically, the $\mathrm{Ge} / \mathrm{TiO}_{2}$ composite thin film contains multiple phases, and it is then difficult to focus on the matrix characteristics. In this section, $\mathrm{Ti}_{1-x} \mathrm{Ge}_{x} \mathrm{O}_{2}$ solid solution is powder-synthesized, and the fundamental properties of solubility range of Ge and the energy band gap are investigated to clarify whether the ternary solid solution exhibits the vis-NIR absorption. 


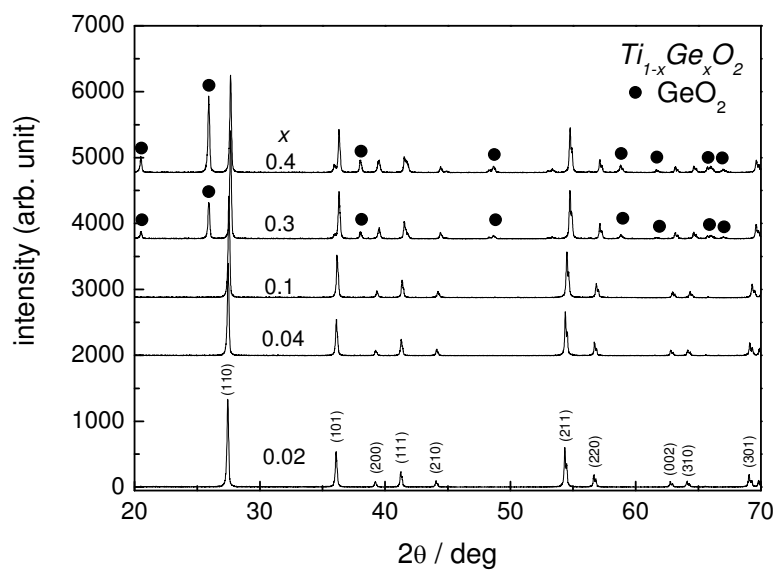

Fig. 2.4. Typical powder XRD patterns of $\mathrm{Ti}_{1-x} \mathrm{Ge}_{x} \mathrm{O}_{2}$ solid solution with respect to $x$. Filled circle indicates $\mathrm{GeO}_{2}$ (after Abe , 2009).

In a previous section, $\mathrm{Ge}$ nanogranules and $\mathrm{TiO}_{2}$ matrix were thermally crystallized at an annealing temperature of $873 \mathrm{~K}$ (Abe et al., 2008). Accordingly, a similar temperature of $923 \mathrm{~K}$ was preliminary adopted to synthesize the $\mathrm{Ti}_{1-x} \mathrm{Ge}_{x} \mathrm{O}_{2}$ solid solution. In this case, four samples $(x=0.05,0.1,0.2$, and 0.3$)$ were mixed and heat-treated for 20 days to achieve thermal equilibrium. However, a single phase of the $\mathrm{Ti}_{1-x} \mathrm{Ge}_{x} \mathrm{O}_{2}$ solid solution could not be obtained, forming two phases of $\mathrm{GeO}_{2}$ and anatase-structured $\mathrm{TiO}_{2}$ according to the XRD pattern. For reference, there was a slight decrease in the lattice constant at $x=0.05$ estimated from the (004) reflection of anatase structure in comparison with those of the $\mathrm{TiO}_{2}$ standard powder, and gradually increased with increasing $x$ in the range exceeding 0.05 . Thus, the solubility limit of Ge was found to be quite narrow (less than 0.05) at 923K. In addition, no energy shift of the optical absorption edge can be seen with respect to $x$. Therefore, an adequately high temperature of $1273 \mathrm{~K}$ is alternatively adopted here in anticipation of a wide solubility range of Ge.

Figure 2-4 depicts typical powder XRD pattern of the $\mathrm{Ti}_{1-x} \mathrm{Ge}_{x} \mathrm{O}_{2}$ solid solution. In the range below 0.1, all the XRD peaks can be assigned to rutile structure and shift toward greater angle as $x$ increases owing to the difference in ionic radii between $\mathrm{Ti}$ and $\mathrm{Ge}$ (Shannon, 1976; Takahashi et al., 2006). In addition, an XRD peak of $\mathrm{GeO}_{2}$ cannot be observed within the precision of the experimental technique. Such peak shift was also observed on the $\mathrm{TiO}_{2^{-}}$ $\mathrm{GeO}_{2}$ solid solution synthesized through sol-gel method within a Ge concentration range below $10 \mathrm{~mol} \%$ (Kitiyanan et al., 2006) or $1.5 \mathrm{~mol} \%$ (S. Chatterjee \& A. Chatterjee, 2006). It is suggested that the present sample possibly forms a solid solution of $\mathrm{Ti}_{1-x} \mathrm{Ge}_{x} \mathrm{O}_{2}$. The solubility range of $\mathrm{Ge}$ is therefore found to be enlarged as a result of elevating the temperature from 923 to $1273 \mathrm{~K}$. The standard powder of $\mathrm{TiO}_{2}$ employed here has anatase structure, since the matrix of the $\mathrm{Ge} / \mathrm{TiO}_{2}$ composite thin films had anatase-dominant structure (Abe et al., 2008b). However, the product thus powder-synthesized resulted in rutile structure because of phase transition from anatase to rutile at 973K (The Mark Index, 1968). In contrast, the $\mathrm{GeO}_{2}$ peaks, which are indicated by a filled circle, begin to appear in the range exceeding 0.3. Their peak positions seem to remain the same with respect to $x$, suggesting no solubility range of $\mathrm{Ti}$ in $\mathrm{GeO}_{2}$ at $1273 \mathrm{~K}$. The two phases of the $\mathrm{Ti}_{1-x} \mathrm{Ge}_{x} \mathrm{O}_{2}$ and $\mathrm{GeO}_{2}$ are therefore formed in such concentration range. 


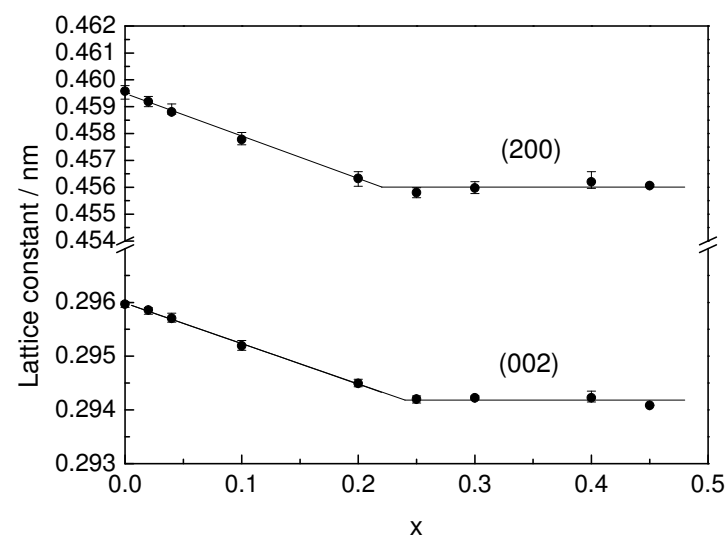

Fig. 2.5. Lattice constant of $\mathrm{Ti}_{1-x} \mathrm{Ge}_{x} \mathrm{O}_{2}$ solid solution vs Ge concentration (after Abe , 2009).

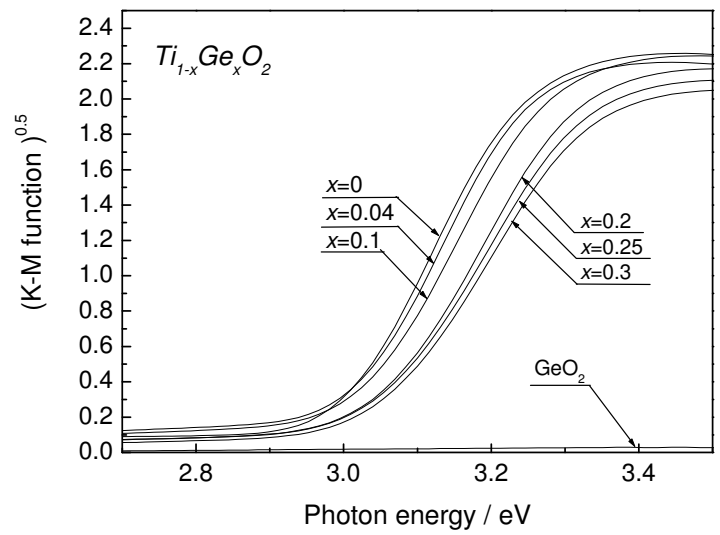

Fig. 2.6. Typical optical absorption spectra of $\mathrm{Ti}_{1-x} \mathrm{Ge}_{x} \mathrm{O}_{2}$ solid solution vs $\mathrm{Ge}$ concentration (after Abe , 2009).

Next, the solubility limit of Ge in the $\mathrm{Ti}_{1-x} \mathrm{Ge}_{x} \mathrm{O}_{2}$ is determined through the variation of the lattice constant. Figure 2-5 depicts the lattice constant of the $\mathrm{Ti}_{1-x} \mathrm{Ge}_{x} \mathrm{O}_{2}$ solid solution as a function of $x$. Here, the lattice constant of the tetragonal system is estimated from the (200) and (002) reflections. Their peak intensities were found to be relatively weak (Fig. 2-4), but the peak position can be distinctly determined from Lorentzian fitting of the spectra, containing a measurement error of about $0.06 \mathrm{deg}$ in $2 \theta$ as a result of four repetitive measurements. Accordingly, the lattice constant results in containing a maximum calculation error of about $0.0006 \mathrm{~nm}$. In the preliminary experiment, a mass reduction during the heat treatment was found to be less than $0.1 \%$ in standard powders of $\mathrm{TiO}_{2}$ and $\mathrm{GeO}_{2}$, suggesting a small amount of sublimation. The nominal content of Ge is therefore employed here as a composition of the product. It is clearly seen in the figure that the lattice constant in both reflections is first decreased linearly in proportion to $x$, and becomes constant irrespective of $x$ in the range exceeding 0.25. According to Vegard's law (Vegard, 1921), an on-setting composition $x$ to deviate from the linearity is regarded as a solubility 
limit of Ge. It is therefore determined to be $0.23 \pm 0.01$ at $1273 \mathrm{~K}$, having 0.22 at $(200)$ and 0.24 at (002) reflection. Thus, the two-phase region consistently involves the fixed composition of $\mathrm{Ti}_{0.77} \mathrm{Ge}_{0.23} \mathrm{O}_{2}$ and $\mathrm{GeO}_{2}$. It can be clearly explained in terms of Gibb's phase rule. Specifically, the number of degrees of freedom is simply estimated to be 1 , since the present ternary system has a component of 2 . Thus, the state of the system is completely fixed at a given temperature of $1273 \mathrm{~K}$. Based on these results, the relation between the lattice constant $L(\mathrm{~nm})$ and $x$ in the solubility range is expressed as follows: $L=0.4595-0.0162 x$ at (200) reflection and $L=0.2960-0.0075 x$ at (002) reflection.
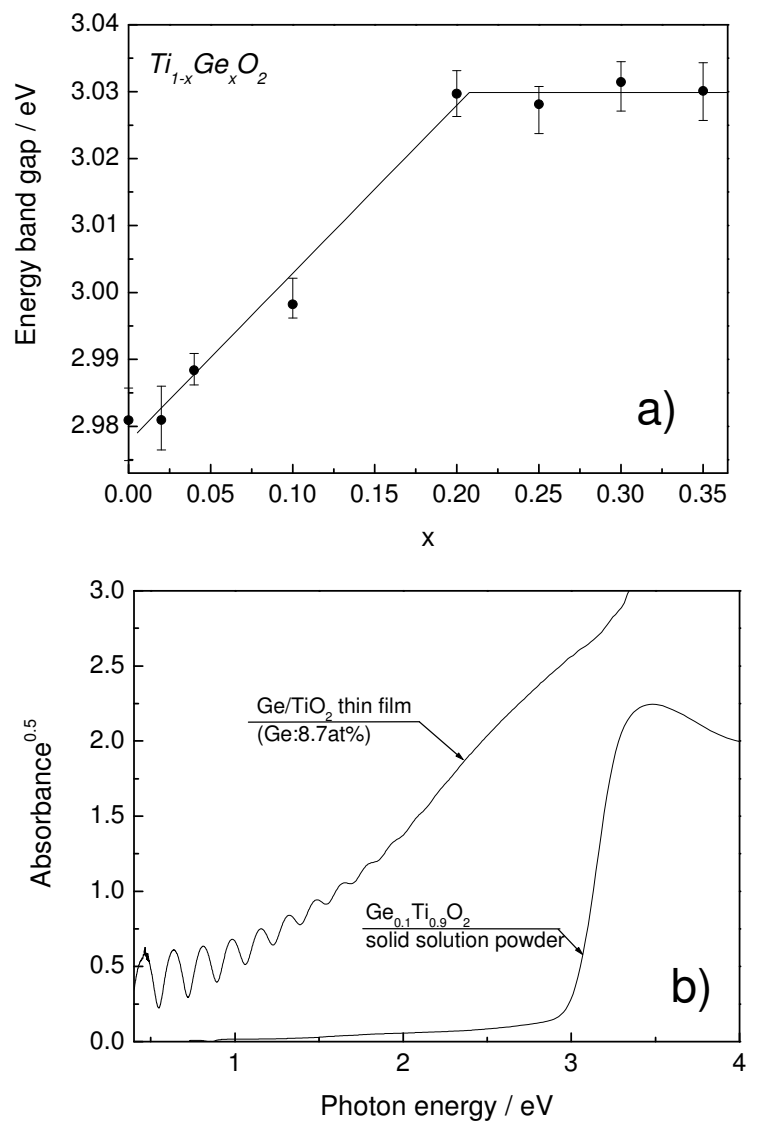

Fig. 2.7. (a) Energy band gap of $\mathrm{Ti}_{1-x} \mathrm{Ge}_{x} \mathrm{O}_{2}$ solid solution at room temperature vs $\mathrm{Ge}$ concentration. (b) Absorption spectra of the $\mathrm{Ge} / \mathrm{TiO}_{2}$ thin film and a solid solution of the $\mathrm{Ti}_{1-x} \mathrm{Ge}_{x} \mathrm{O}_{2}$ powder (after Abe , 2009).

In comparison, the lattice constant of the matrix in the $\mathrm{Ge} / \mathrm{TiO}_{2}$ composite thin films also decreased with increasing Ge concentration, ranging from 0.9495 to $0.9400 \mathrm{~nm}$ estimated from the (004) reflection of anatase structure. In this case, the postannealing was performed at $873 \mathrm{~K}$ for $60 \mathrm{~min}$. Such decreasing tendency of the lattice constant is the same as those of the $\mathrm{Ti}_{1-x} \mathrm{Ge}_{x} \mathrm{O}_{2}$ powder despite the fact that the crystal structure is different in both samples, 
having a rutile structure for the powder and an anatase structure for the composite films. Therefore, the matrix of the composite film possibly formed a solid solution of $\mathrm{Ti}_{1-x} \mathrm{Ge}_{x} \mathrm{O}_{2}$. Subsequently, optical absorption should be investigated regardless of whether the solid solution exhibits the vis-NIR absorption.

Figure 2-6 plots the optical absorption spectra of the powder-synthesized $\mathrm{Ti}_{1-x} \mathrm{Ge}_{x} \mathrm{O}_{2}$ solid solution. These spectra are derived from the square root of Kubelka-Munk function (Kubelka \& Munk, 1931) because of the indirect band gap structure of $\mathrm{TiO}_{2}(\mathrm{Macfarlane}$ et al., 1957). For comparison, the spectrum of $\mathrm{GeO}_{2}$ is also shown. It is clearly seen that the $\mathrm{GeO}_{2}$ is appreciably transparent in the measured range from 2.7 to $3.5 \mathrm{eV}$, whereas the optical absorption edge of the $\mathrm{Ti}_{1-x} \mathrm{Ge}_{x} \mathrm{O}_{2}$ can be clearly observed at approximately $3 \mathrm{eV}$, and shift to the greater energy region as $x$ increases. Therefore, the solid solution of $\mathrm{Ti}_{1-x} \mathrm{Ge}_{x} \mathrm{O}_{2}$ is found to unexhibit the vis-NIR absorption.

Just for reference, the band gap can be estimated from a linear extrapolation to zero of the optical absorption edge, and is then summarized in Fig. 2-7(a). Error bars indicative of the possible variation in energy gap are used to plot the data. The energy band gap increases monotonically from 2.98 to $3.03 \mathrm{eV}$ with respect to $x$, and becomes constant in the range exceeding 0.25 . The energy shift is therefore achieved to be $0.05 \mathrm{eV}$ at a solubility limit of 0.23. In fact, the $\mathrm{Ge} / \mathrm{TiO}_{2}$ composite thin films were compositionally optimized at a relatively low Ge concentration of 6 to 9at.\% (Abe et al., 2008b), which indicates the total amount of Ge contained in both the matrix and the nanogranules. Hence, the energy shift in the matrix of the composite thin film is considered to be negligibly small (less than $0.01 \mathrm{eV}$ ). From these results, the matrix of the $\mathrm{Ge} / \mathrm{TiO}_{2}$ composite thin films possibly formed a solid solution of $\mathrm{Ti}_{1-x} \mathrm{Ge}_{x} \mathrm{O}_{2}$ during the post annealing, but did not exhibit the vis-NIR absorption. Figure 2-7(b) depicts the optical absorption spectra of the $\mathrm{Ge} / \mathrm{TiO}_{2}$ thin film and a solid solution of the $\mathrm{Ti}_{1-x} \mathrm{Ge}_{x} \mathrm{O}_{2}$ powder. Here, Ge concentration in the film was analyzed to be 8.7 at. \%, and a similar concentration of $x=0.1$ in the powder was also presented for comparison. The absorption spectrum of the $\mathrm{Ti}_{1-x} \mathrm{Ge}_{x} \mathrm{O}_{2}$ powder was obtained by means of the KubelkaMunk function (Kubelka \& Munk, 1931) through a diffused reflectance spectrum. The visNIR absorption was clearly observed in the $\mathrm{Ge} / \mathrm{TiO}_{2}$ film, while an optical absorption edge of the synthesized powder was observed at UV region. It was therefore concluded that the $\mathrm{Ti}_{1-x} \mathrm{Ge}_{x} \mathrm{O}_{2}$ solid solution unexhibited such vis-NIR absorption.

\subsection{Quantum size effect of $\mathrm{Ge}$ in $\mathrm{TiO}_{2}$ matrix}

In the previous sections, valuable characteristics of the vis-NIR absorption and the anatasedominant structure of $\mathrm{TiO}_{2}$ matrix were simultaneously retained in the $\mathrm{Ge} / \mathrm{TiO}_{2}$ composite thin films. However, it was unclear whether the vis-NIR absorption (Fig. 2-3) was due to the presence of Ge nanogranules, since an X-ray diffraction peak of Ge was not observed in the optimized composition range. In this section, we have investigated the presence of $\mathrm{Ge}$ nanogranules embedded in the anatase-dominant structure of $\mathrm{TiO}_{2}$ thin films, and clarified the reason for the vis-NIR absorption.

Figure 2-8 depicts the size distribution of nanogranules in the $\mathrm{Ge} / \mathrm{TiO}_{2}$ composite thin films. These profiles were estimated from small angle X-ray spectroscopy (SAXS) analysis of Guinier fitting for an experimental result (the inset in Fig.2-8). In this case, Ge chips of 3 and the oxygen ratio of $0.3 \%$ was adopted during the deposition, and Ge concentration was analyzed to be 8.7 at.\%, and the film exhibited the vis-NIR absorption [Fig. 2-7(b)]. In the pinhole-collimated apparatus of SAXS measurement, X-ray was injected perpendicularly to the film surface, providing in-plane structural characteristic. As can be seen in the figure, the 
size profile distributed broadly, and mean radius of nanogranules was estimated to be 1.9 $\mathrm{nm}(3.8 \mathrm{~nm}$ in diameter), ranging the radius from $\sim 0.5$ to $8 \mathrm{~nm}$. The SAXS analysis therefore strongly suggested that nanoscale material was embedded in the film, possibly attributing to Ge nanogranules or another phase of the $\mathrm{Ti}_{1-x} \mathrm{Ge}_{x} \mathrm{O}_{2}$ matrix. Successively, the size of $\mathrm{Ti}_{1-}$ ${ }_{x} \mathrm{Ge}_{x} \mathrm{O}_{2}$ matrix was estimated by HREM.

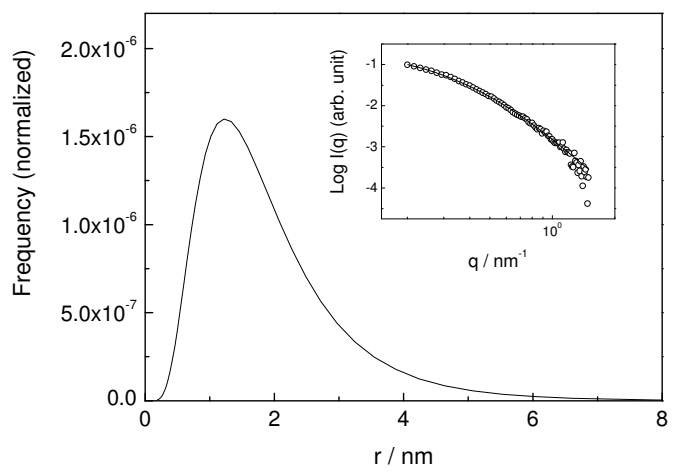

Fig. 2.8. Size distribution of nanogranules derived from the SAXS analysis. The inset depicts SAXS spectrum (after Abe et al., 2008c).
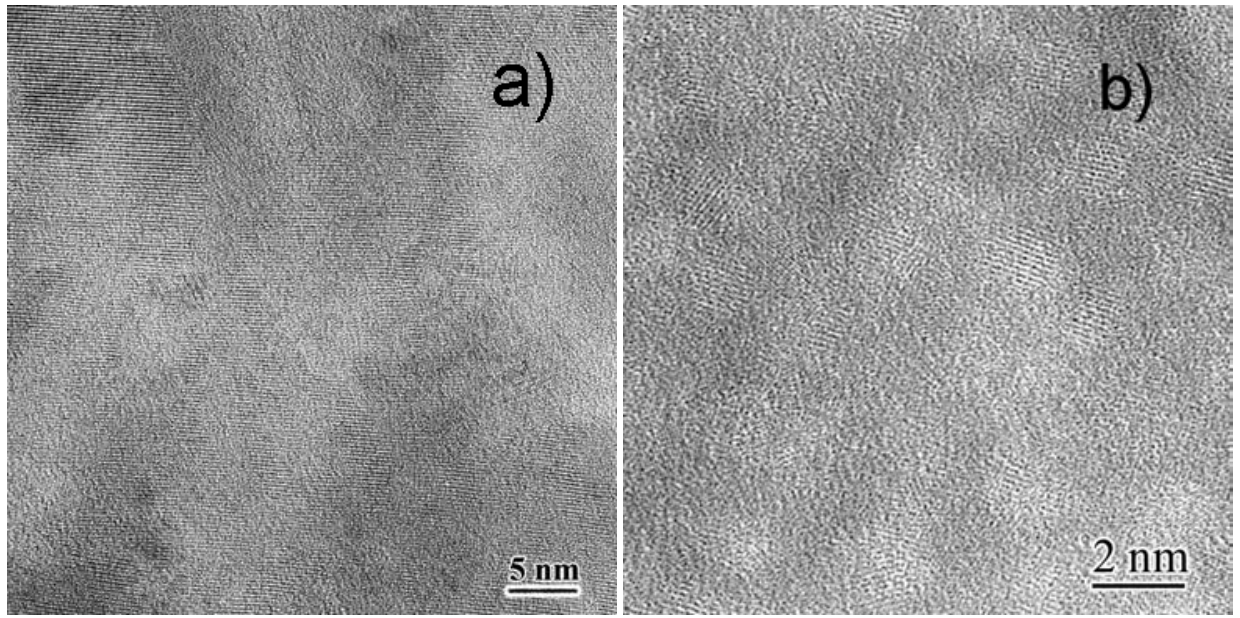

Fig. 2.9. (a) HREM image of anatase structure of the matrix in $\mathrm{Ge} / \mathrm{TiO}_{2}$ thin films (Abe et al., 2008c). (b) HREM image of Ge nanogranules embedded in the matrix (after Abe et al., 2008b).

Figure 2-9(a) presents the HREM image of the anatase-structured matrix at an oxygen ratio of $0.3 \%$. Lattice image of the anatase structure was clearly observed, and size of their grains was estimated to be $\sim 30 \mathrm{~nm}$. The size exceeded that of the nanogranules estimated by SAXS. Figure 2-9(b) presents an HREM image of Ge nanogranules embedded in $\mathrm{Ge} / \mathrm{TiO}_{2}$ composite film at a Ge concentration of 8.7 at.\%. In the figure, the slightly bright contrast 
region with spherical geometry corresponds to Ge nanogranule, and their lattice image can be clearly seen. The average size is estimated to be about $2 \mathrm{~nm}$. Furthermore, their average size is also estimated to be about $5 \mathrm{~nm}$ by SAXS analysis. These estimated sizes are found to be close each other, and the Ge nanogranules are sufficiently small to create the quantum size effect because of the exciton Bohr radius of 24.3nm in Ge (Maeda et al., 1991). Therefore, the shift of optical absorption (Fig. 2-3) is reasonably due to the Ge nanogranules embedded in $\mathrm{Ti}_{1-x} \mathrm{Ge}_{x} \mathrm{O}_{2}$ matrix.

\section{PbSe/ZnSe composite thin films}

Co-sputtering thus employed in the above section is useful for forming a composite thin film consisting of semiconductor nanocrystals embedded in a matrix because of its simple preparation process and consequent low cost. In the material design, based on the heat of formation, nanocrystal and matrix are clearly phase-separated in spite of the co-deposition from multiple sources (Abe et al., 2008b; Ohnuma et al., 1996). However, it is generally found that sputtering techniques often damage a film due to contamination of the fed gas and high-energy bombardment of the film surface. Thermal evaporation in a high-vacuum atmosphere seems to be better as a preparation technique from the point of view of film quality. In addition, the present study focuses on the insolubility of the material system, since simultaneous evaporation from multiple sources often provides a solid solution (Nill, et al., 1973; Holloway \& Jesion, 1982; Abe \& Masumoto, 1999).

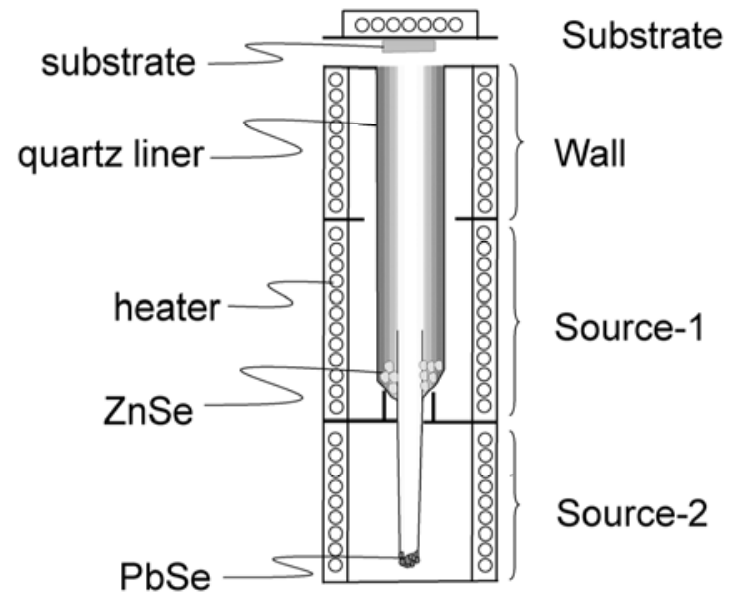

Fig. 3.1. HWD apparatus used in the study. It consists of four electric furnaces for substrate, wall, source-1, and source-2 (after Abe, 2011).

The PbSe-ZnSe system is a candidate for the composite. In the bulk thermal equilibrium state, the mutual solubility range is quite narrow, less than $1 \mathrm{~mol} \%$, at temperatures below 1283K (Oleinik et al., 1982). In addition, a composite thin film of PbSe nanocrystal embedded in ZnSe matrix is capable of exhibiting the quantum size effect because of the relatively large exciton Bohr radius of 46nm in PbSe (Wise, 2000) and the relatively wide band gap of $2.67 \mathrm{eV}$ in ZnSe (Adachi \& Taguchi, 1991). Hence, the optical gap of PbSe nanocrystals will probably be tuned to the maximum solar radiation spectrum. The 
dendritic PbSe nanostructure (Xue, 2009) and ZnSe nanobelt array (Liu, 2009), for instance, are hitherto investigated, but there is no report for one-step synthesis of PbSe/ZnSe composite thin film. Furthermore, an evaporation technique should be carefully selected, since the techniques involving a thermal non-equilibrium state, such as molecular beam epitaxy, increase the solubility limit (Koguchi et al., 1987). The use of HWD, which can provide an atmosphere near thermal equilibrium, is therefore indicated here (Lopez-Otero, 1978). Based on these considerations, one-step synthesis of a PbSe/ZnSe composite thin film was investigated by simultaneous HWD from multiple sources.

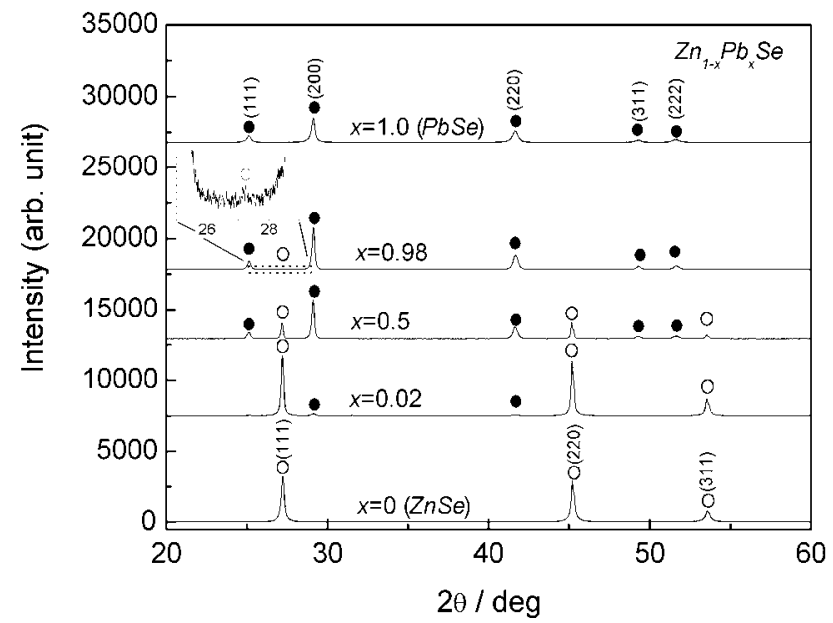

Fig. 3.2. $\mathrm{XRD}$ pattern of powder-synthesized $\mathrm{Zn}_{1-x} \mathrm{~Pb} \mathrm{~b}_{x} \mathrm{Se}$ with respect to $x$. Dots indicate $\mathrm{PbSe}$ and circles indicate ZnSe (after Abe, 2011).

A PbSe/ZnSe composite thin film was prepared by the HWD method. Figure 3-1 is a schematic diagram of the HWD apparatus used. There were four electric furnaces in the apparatus, designated as substrate, wall, source-1, and source-2. Each temperature could be controlled independently. In the HWD method, deposition and re-evaporation are continuously repeated upon a film surface, resulting in achieving a state near thermal equilibrium (Lopez-Otero, 1973). PbSe and ZnSe were used as evaporation sources and were synthesized from elements of $\mathrm{Pb}, \mathrm{Zn}$, and Se with $6 \mathrm{~N}$ purity. The PbSe and $\mathrm{ZnSe}$ sources were located at furnaces of source- 2 and source- 1 for simultaneous evaporation to a glass substrate (Corning \#7059). Here, the temperatures were kept constant at $573 \mathrm{~K}$ for the substrate, $773 \mathrm{~K}$ for the wall, and $973 \mathrm{~K}$ for source- 1 (ZnSe). The source-2 (PbSe) temperature was varied from 763 to $833 \mathrm{~K}$ to provide different PbSe concentrations.

The bulk PbSe-ZnSe phase diagram is now revealed at ZnSe concentrations below 45at.\% (Pb-rich side) (Oleinik et al., 1982), although the phase diagram of the Zn-rich side still remains unclear. Powder synthesis of a PbSe-ZnSe system was investigated prior to investigating the film preparation. Figure 3-2 depicts the powder XRD pattern of the $Z_{n_{1}}$ ${ }_{x} \mathrm{~Pb}_{x} \mathrm{Se}$ system. In the powder synthesis, the bulk PbSe and ZnSe thus synthesized was used as starting materials. The desired composition of the system was prepared in an agate mortar and vacuum-sealed in a quartz tube for heat treatment at $1273 \mathrm{~K}$ for $48 \mathrm{~h}$. Finally, the samples were successively water-quenched to maintain the solubility range at 
a synthesis temperature then crushed into powder for the following experiment setup. At $x=0$, all of the XRD peaks are assigned to the zinc-blend structure of ZnSe, with a lattice constant of $0.5669 \mathrm{~nm}$, estimated from the XRD peaks in a high- $2 \theta$ range from $100^{\circ}$ to $155^{\circ}$, using the Nelson-Riley function (Nelson \& Riley, 1945). The XRD peak of PbSe with an $\mathrm{NaCl}$ structure appears at $\mathrm{Pb}$ concentrations exceeding 0.02. The lattice constant of the ZnSe at $x=0.02$ is the same as at $x=0$, within the precision of the experiment technique. This result indicates that the solubility range of $\mathrm{Pb}$ in $\mathrm{ZnSe}$ is negligible. In contrast, the lattice constant of PbSe is estimated to be $0.6121 \mathrm{~nm}$ at $x=1.0$ and $0.6117 \mathrm{~nm}$ at $x=0.98$. A slight decrease in the lattice constant is seen in PbSe, due to the difference in ionic radii of $\mathrm{Pb}$ and $\mathrm{Zn}$. Weak XRD peaks of ZnSe are also observed at $x=0.98$ as seen in the inset for easier viewing. This result indicates that the solubility range of $\mathrm{Zn}$ in PbSe is less than 0.02 at $1273 \mathrm{~K}$. The result is in good agreement with the previous result (Oleinik et al., 1982). The phase separation of the PbSe-ZnSe system is thus also seen on the Zn-rich side in the thermal-equilibrium state. The film preparation for $\mathrm{PbSe} / \mathrm{ZnSe}$ composite is next investigated based on these results.

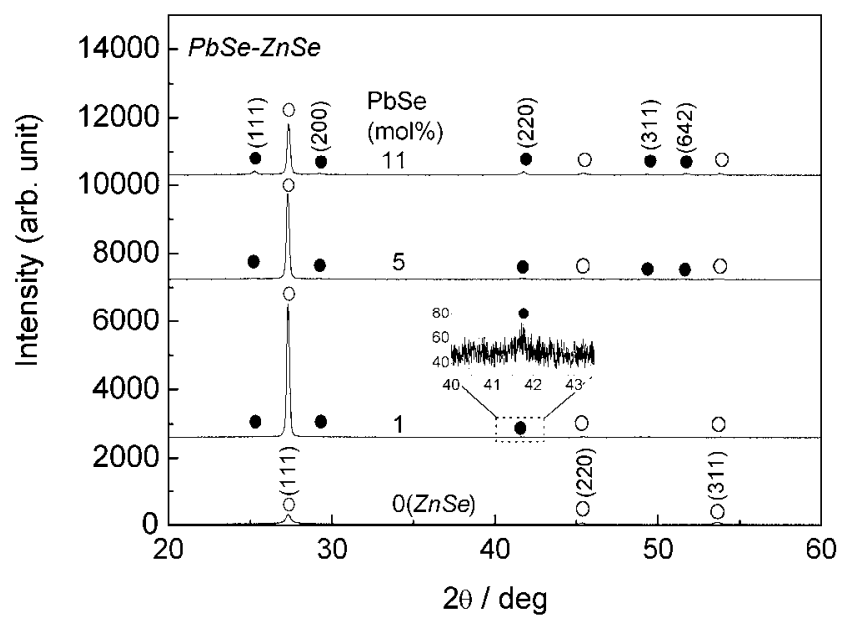

Fig. 3.3. XRD pattern of the PbSe/ZnSe composite thin films. Dots indicate PbSe and circles indicate ZnSe (after Abe, 2011).

The two sources were simultaneously evaporated to prepare a $\mathrm{PbSe} / \mathrm{ZnSe}$ composite thin film. In the apparatus used, thermal radiation from the wall- and the source-furnace induced an unintentional increase of the substrate temperature up to $515 \mathrm{~K}$ without use of the substrate-furnace. The deposition rate of the film was almost the same irrespective of the substrate temperature in the range from $515 \mathrm{~K}$ to $593 \mathrm{~K}$. A homogeneous color is observed visually in these films. Above a substrate temperature of 593K, the deposition rate abruptly decreased with increasing temperature, since re-evaporation of PbSe from the film surface became dominant. The films visually exhibit an inhomogeneous yellowish and metallic color, probably caused by a significant reduction in the PbSe while the ZnSe remained, due to the relatively high vapor pressure of PbSe (Mills, 1974). The wall temperature also induced similar behavior. A substrate temperature of $573 \mathrm{~K}$ and a wall temperature of $773 \mathrm{~K}$ are therefore adopted throughout the present study. 
Figure 3-3 depicts the XRD pattern for the PbSe/ZnSe composite thin films. The weak XRD peak of $\mathrm{PbSe}$ at $1 \mathrm{~mol} \%$ is enlarged in the inset for easier viewing. At a PbSe concentration of $0 \mathrm{~mol} \%$ (i.e., pure ZnSe), polycrystalline ZnSe with a zinc-blend structure is observed, with PbSe phase appearing at concentrations exceeding $1 \mathrm{~mol} \%$. The solubility range of $\mathrm{Pb}$ in ZnSe is therefore found to be quite narrow, less than $1 \mathrm{~mol} \%$, corresponding well to the bulk result (Fig. 3-2). The composite films thus deposited on a glass substrate exhibit a reasonably polycrystalline structure, but dominant (111) growth is seen in the ZnSe phase irrespective of $x$. At $1 \mathrm{~mol} \%$, the lattice constant at the PbSe (220) peak is estimated to be $0.6118 \mathrm{~nm}$, close to that of the bulk result (Fig. 3-2). This result suggests that there is also a narrow solubility range on the Pb-rich side. The phase-separating PbSe-ZnSe system is therefore maintained not only in the bulk product, but also in the film thus obtained, despite the simultaneous evaporation from multiple sources. This result demonstrates that an atmosphere near thermal equilibrium was achieved in the HWD apparatus used.

Figure 3-4(a) presents a bright-field TEM image of the PbSe/ZnSe composite thin film containing $5 \mathrm{~mol} \% \mathrm{PbSe}$. Dark isolated grains with sizes of $25 \mathrm{~nm}$ to $50 \mathrm{~nm}$ are seen dispersed along the grain boundary of the bright area. Figures 3-4(b-e) present an scanning transmission electron microscopy (STEM) - energy dispersive spectroscopy (EDX) elemental mapping of the sample through X-ray detection of $\mathrm{Zn} \mathrm{K}$ (red), Se K (blue), and Pb L (green). Similar morphology is also seen in the bright-field STEM image [Fig. 3-4(b)]. The dark grains indicate the absence of elemental Zn [Fig. 3-4(c)] and the presence of Se and Pb [Figs. 3-4 (d and e)]. It is thus determined that the dark grains are nanocrystalline PbSe. The other region is widely covered with the elements Zn and Se [Figs. 3-4 (c and d)], reasonably assumed to compose $\mathrm{ZnSe}$. It is therefore determined that isolated PbSe nanocrystals are dispersed in the ZnSe matrix. The nanocrystals are estimated to be sufficiently small to exhibit the quantum-size effect because of the exciton Bohr radius of 46nm in PbSe (Wise, 2000).

Figure 3-5 depicts optical absorption spectra for the PbSe/ZnSe composite thin films. For comparison, the spectrum of a pure ZnSe thin film is also presented in the figure. PbSe and ZnSe have direct band structures (Theis, 1977; Zemel et al., 1965) and the absorbance squared is employed here. At a $0 \mathrm{~mol} \% \mathrm{PbSe}$, the optical absorption edge of ZnSe is clearly observed at $2.7 \mathrm{eV}$. Weak absorption then broadly appears at a PbSe concentration of $1 \mathrm{~mol} \%$ in the visible region, together with the optical absorption edge of ZnSe. Such multiple absorptions are also seen in the spectra at concentrations up to $7 \mathrm{~mol} \%$, indicating the obvious phase separation of the PbSe-ZnSe system. The broad absorption edge shifts toward the lower-energy region as the PbSe content increases. In particular, onset absorption can be confirmed at approximately $1.0 \mathrm{eV}$ at $16 \mathrm{~mol} \% \mathrm{PbSe}$, favorably covering the desirable energy region for high conversion efficiency (Loferski, 1956). Therefore, it should be noted that the $\mathrm{PbSe} / \mathrm{ZnSe}$ composite thin film exhibits the valuable characteristic of vis-NIR absorption.

However, it is unclear whether the shift of the optical absorption edge is due to the PbSe nanocrystals, since the mean grain size of the PbSe remains almost the same at $27 \mathrm{~nm}$ irrespective of the PbSe content, according to the XRD result (Fig. 3-3) using Scherrer's equation (Scherrer, 1918). A PbSe-ZnSe solid-solution system cannot provide continuous change of the energy band gap because of the quite narrow solubility range (Fig. 3-3). In contrast, the PbSe nanocrystals are sufficiently smaller than the exciton Bohr radius of PbSe (Fig. 3-4). Therefore, this obvious shift is assumed to be responsible for the quantum-size effect of the PbSe nanocrystals embedded in the ZnSe matrix. The minimal appearance of infrared absorption at $16 \mathrm{~mol} \% \mathrm{PbSe}$ strongly suggests that relatively large-scale PbSe grains are partially involved in the composite film, since the energy band gap of bulk PbSe is 
$0.27 \mathrm{eV}$ (Zemel et al., 1965). Another TEM image also indicates the presence of relatively large PbSe crystals of approximately 100nm, even with a small amount of $5 \mathrm{~mol} \% \mathrm{PbSe}$ (not shown here). Hence, the mean grain size of the PbSe is bimodally distributed in the composite. These large-scale PbSe grains probably dominate the full width at half_maximum value of the XRD peak, resulting in no obvious relation between the optical absorption shift and the PbSe grain size. The size control of the nanocrystalline PbSe is therefore insufficient in the present study. The substrate temperature thus adopted seems to assist in the aggregation of PbSe nanocrystals. However, a one-step synthesis of the composite package has the potential to lead to low-cost production of next-generation solar cells.

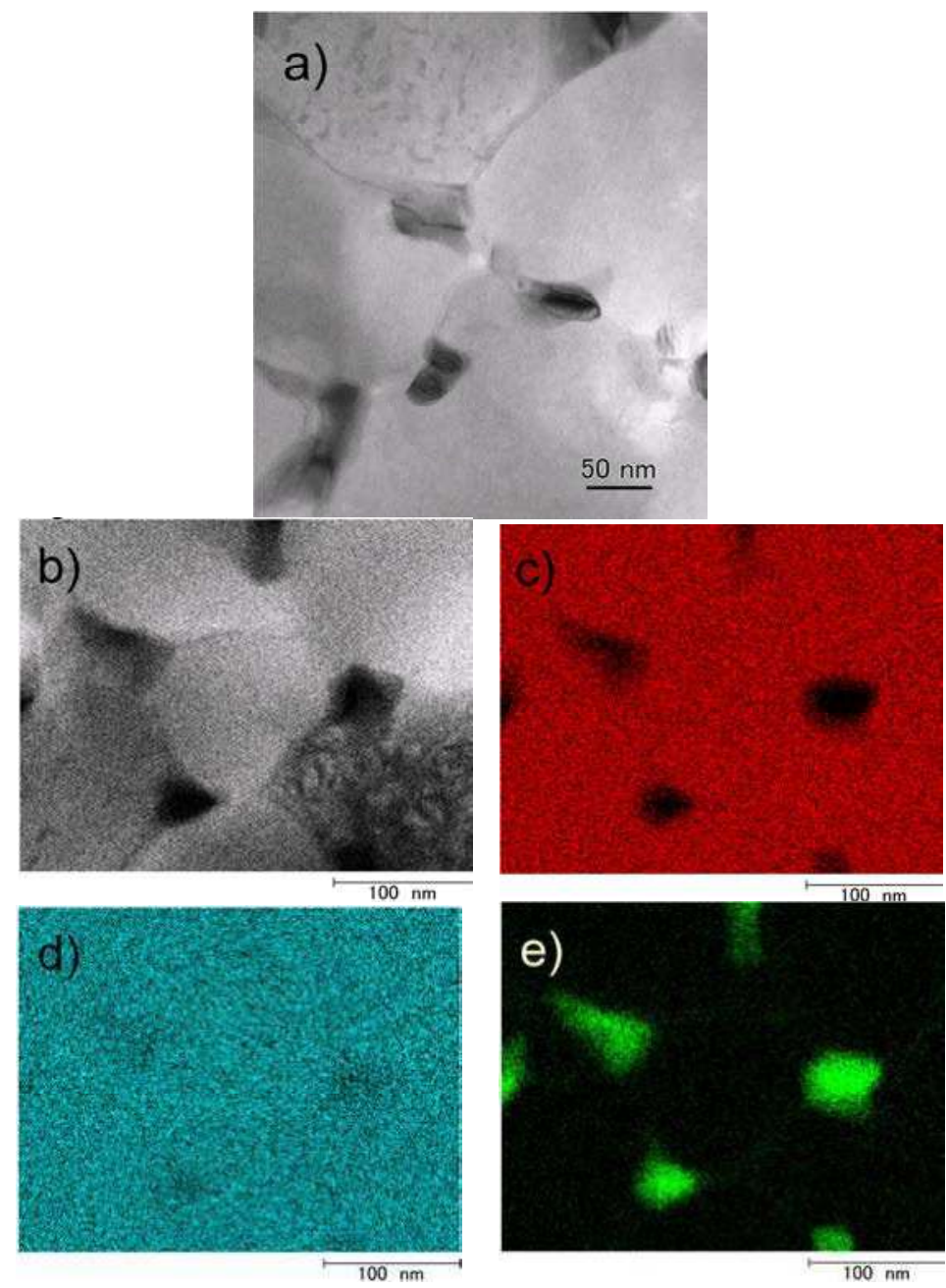

Fig. 3.4. Direct observation of PbSe/ZnSe composite thin film containing $5 \mathrm{~mol} \% \mathrm{PbSe}$. (a) Bright-field TEM image. (b) Bright-field image of STEM mode. (c) Elemental mapping of Zn (red), (d) Se (blue), and (e) Pb (green) (after Abe, 2011). 


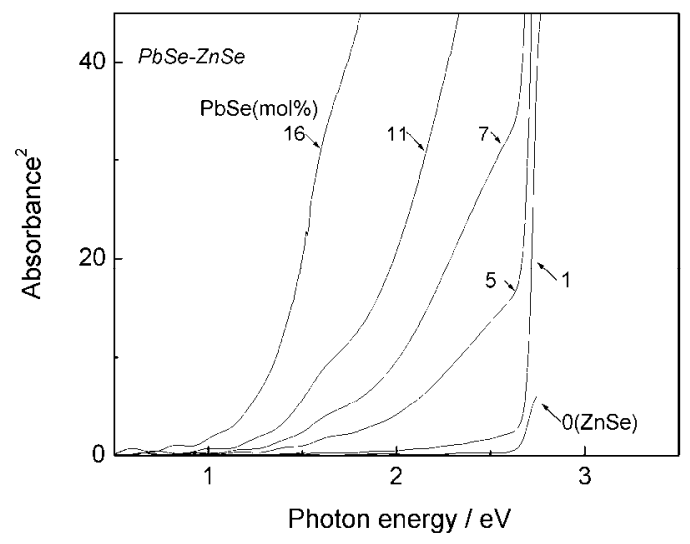

Fig. 3.5. Optical absorption spectra for PbSe/ZnSe composite thin films (after Abe, 2011).

\section{Conclusion}

This chapter has been focused on one-step physical synthesis of $\mathrm{Ge} / \mathrm{TiO}_{2}$ and $\mathrm{PbSe} / \mathrm{ZnSe}$ composite thin film as candidate materials for quantum dot solar cell. It should be pointed out in the $\mathrm{Ge} / \mathrm{TiO}_{2}$ that the anatase-dominant structure appears in the restricted composition range as a result of optimization of Ge chip numbers and additional oxygen ratio in argon. Furthermore, their optical absorption edge is obviously shifted to vis-NIR region. The solubility range of $\mathrm{Ge}$ in the $\mathrm{Ti}_{1-x} \mathrm{Ge}_{x} \mathrm{O}_{2}$ powder is estimated to be $0.23 \pm 0.01$ at $1273 \mathrm{~K}$. In addition, their optical absorption edge is obviously shifted to the UV region as $x$ increases. Thus, the $\mathrm{Ti}_{1-x} \mathrm{Ge}_{x} \mathrm{O}_{2}$ solid solution does not exhibit the vis-NIR absorption. In contrast, SAXS and HREM results clearly indicated that the Ge nanogranules were embedded in the matrix. The size was sufficiently small to appear the quantum size effect. Thus, the both valuable characteristics are simultaneously retained in the $\mathrm{Ge} / \mathrm{TiO}_{2}$ composite films. In the PbSe/ZnSe, the solubility limit of $\mathrm{Pb}$ in $\mathrm{ZnSe}$ is quite narrow, less than $1 \mathrm{~mol} \%$ in the film form, indicating that an atmosphere near thermal equilibrium is achieved in the apparatus used. Elemental mapping indicates that isolated PbSe nanocrystals are dispersed in the $\mathrm{ZnSe}$ matrix. The optical absorption edge shifts toward the lower-photon-energy region as the PbSe content increases. In particular, onset absorption can be confirmed at approximately $1.0 \mathrm{eV}$ with $16 \mathrm{~mol} \% \mathrm{PbSe}$, favorably covering the desirable energy region for high conversion efficiency. The insolubility material system and the HWD technique enable a one-step synthesis of $\mathrm{PbSe} / \mathrm{ZnSe}$ composite thin film.

\section{Acknowledgment}

The present work was supported in part by a Grant-in-Aid for Scientific Research from the Japan Society for the Promotion of Science (No.21360346). The author is grateful to Dr. M. Ohnuma [National Institute for Materials Science (NIMS), Tsukuba, Japan], Dr. D. H. Ping (NIMS), and Dr. S. Ohnuma [Research Institute for Electromagnetic Materials (RIEM), Sendai, Japan] for collaborating in this work. The author gratefully acknowledges the valuable comments and continuous encouragement of President T. Masumoto (RIEM). The author is also grateful to Mr. N. Hoshi and Mr. Y. Sato (RIEM) for assisting in the experiments. 


\section{References}

Abe, S. \& Masumoto, K. (1999). Compositional plane and properties of solid solution semiconductor $\mathrm{Pb}_{1-x} \mathrm{Ca}_{x} \mathrm{~S}_{1-y} \mathrm{Se}_{y}$ for mid-infrared lasers, Journal of Crystal Growth, Vol.204, pp. 115-121.

Abe, S, Ohnuma, M, Ping, D. H., Ohnuma, S. (2008a). Single dominant distribution of Ge nanogranule embedded in Al-oxide thin film, Journal of Aplied Physics, Vol. 104, pp. 104305 1-3.

Abe, S, Ohnuma, M, Ping, D. H., Ohnuma, S (2008b). Anatase-Dominant Matrix in Ge/TiO 2 Thin Films Prepared by RF Sputtering Method , Applied Physics Express, Vol. 1, pp. 095001 1-3.

Abe, S, Ohnuma, M, Ping, D. H., Ohnuma, S (2008c). Preparation of Ge nanogranules embedded in Anatase-dominant $\mathrm{TiO}_{2}$ thin films by RF sputtering, Proceedings of $14^{\text {th }}$ International Conference on Thin Films (ICTF 14), pp.101-104.

Abe, S (2009). Solubility Range and Energy Band Gap of Powder-Synthesized $\mathrm{Ti}_{1-x} \mathrm{Ge}_{x} \mathrm{O}_{2}$ Solid Solution, Japanese Journal of Applied Physics, Vol. 48, pp. 081605 1-3

Abe, S (2011). One-step synthesis of PbSe/ZnSe composite thin film, Nanoscale Research Letters Vol. 6, pp.324 1-6.

Adachi, S. \& Taguchi, T. (1991). Optical properties of ZnSe,: Physical Review B, Vol. 43, pp. 9569-9577.

Chatterjee, S. Goyal, A. \& Shah, I. (2006). Inorganic nanocomposites for next generation photovoltaics, Materials Letters. Vol.60, pp. 3541-3543.

Chatterjee, S. \& Chatterjee, A. (2008). Optoelectronic properties of Ge-doped $\mathrm{TiO}_{2}$ nanoparticles. Japanese Journal of Applied Physics, Vol. 47, pp. 1136-1139.

Chatterjee, S. (2008). Titania-germanium nanocomposite as a photovoltaic material, Solar Energy, Vol.82, pp. 95-99.

Holloway, H. \& Jesion, G. (1982). Lead strontium sulfide and lead calcium sulfide, two new alloy semiconductors, Physical Review B, Vol. 26, pp. 5617-5622.

Hoyer, P. \& Könenkamp, R. (1995). Photoconduction in porus $\mathrm{TiO}_{2}$ sensitized by $\mathrm{PbS}$ quantum dots, Appied Physics Letters, Vol. 66, pp. 349-351.

Kitiyanan, A. Kato, T. Suzuki, Y. \& Yoshikawa, S. (2006). The use of binary $\mathrm{TiO}_{2}-\mathrm{GeO}_{2}$ oxide electrodes to enhanced efficiency of dye-sensitized solar cells, Journal of Photochemistry and Photobiology A, Vol. 179, pp. 130-134.

Koguchi, N. Kiyosawa, T.\& Takahashi, S. (1987). Double hetero structure of $\mathrm{Pb}_{1-x} \mathrm{Cd}_{x} \mathrm{~S}_{1-y} \mathrm{Se}_{y}$ lasers grown by molecular beam epitaxy, Journal of Crystal Growth, Vol. 81, pp. 400-404.

Kolodinski, S. Werner, J. H. Wittchen, T. \& Queisser, H.J. (1993). Quantum efficiencies exceeding unity due to impact ionization in silicon solar cells, Applied Physics Letters, Vol. 63, pp. 2405-2407.

Kubachevski, O \& Alcock, C. B. (1979). Metallurgical Thermochemistry, Pergamon.

Kubelka, P. \& Munk, F. (1931). Ein Beitrag zur Optik der Far-banstriche, Zeitschrift Technische Physik Vol. 12, pp. 593-601.

Landsberg, P. T. Nussbaumer, H. \& Willeke, G. (1993). Band-band impact ionization and solar cell efficiency , Journal of Applied Physics, Vol. 74, pp. 1451-1452.

Liu, D. \& Kamat, P. V. (1993). Photoelectrochemical behavior of thin CdSe and coupled $\mathrm{TiO}_{2} /$ CdSe semiconductor films, Journal of Physical Chemistory, Vol. 97, pp. 10769-10773.

Liu, J. \& Xue, D. (2009). Solution-based route to semiconductor film: Well-aligned ZnSe nanobelt arrays, Thin Solid Films, Vol. 517, pp. 4814-4817.

Loferski, J. J. (1956). Theoretical considerations covering the choice of the optinum semiconductor for photovoltaic solar energy conversion, Journal of Applied Physics, Vol. 27, pp.777-784. 
Lopez-Otero, A. (1978). Hot wall epitaxy, Thin Solid Films, Vol. 49, pp. 3-57.

Macfarlane, G. G. McLean, T. P. Quarrington, J. E. \& Roberts, V. (1957). Fine structure in the absorption-edge spectrum of Ge, Physical Review , Vol. 108, pp. 1377-1383.

Maeda, Y. Tsukamoto, N. Yazawa, Y. Kanemitsu, Y. \& Masumoto, Y. (1991). Visible photoluminescence of Ge microcrystals embeddded $\mathrm{inSiO}_{2}$, Applied Physics Letters, Vol. 59, pp. 3168-3170.

Mills, K. C. (1974). Thermodynamic data for inorganic sulphide, selenides and Tellurides. Butterworth.

Nelson, J. B. \& Riley, D. P. (1945). An experimental investigation of extrapolation methods in the derivation of accurate unit-cell dimensions of crystals, Proceedings of Physical Society Vol. 57, pp. 160.

Nill, K. W. Sreauss, A. J. \& Blum, F. A. (1973). Tunable cw Pb0.98Cd0.02S diode lasers emitting at $3.5 \mu \mathrm{m}$ : Applications to ultrahigh-resolution spectroscopy, Applied Physics Letters Vol. 22, pp. 677-679.

Nozik, A. J. (2002). Quantum dot solar cells, Physics E, Vol. 14, pp.115-120.

Ohnuma, S. Fujimori, H. Mitani, S. \& Masumoto, T. (1996). High-frequency magnetic properties in metal-nonmetal granular films, Journal of Applied Physics, Vol. 79, pp. 5130-5135.

Oleinik, G.S. Mizetskii, P.A. \& Nizkova, A.I. (1982). Nature of the interaction between lead and zic chalcogenides, Inorganic Materials, Vol. 18, pp. 734-735.

Scherrer, P. (1918). Bestimmung der Größe und der inneren Struktur von Kolloidteilchen mittels Röntgenstrahlen, Göttinger Nachrichten, Vol. 2, pp. 98-100.

Shannon, R. D. (1976). Revised effective ionic radii and systematic studies of interatomic distances in halides and chalcogenides, Acta Crystallography, Sect. A, Vol. 32, pp. 751-767.

The Merck Index (Merck \& Co, New Jersey, 1968) 8th ed., p. 1054.

Takahasi, Y. Kitamura, K. Iyi, N. \& Inoue, S. (2006). Phase-stability and photoluminescence of $\mathrm{BaTi}(\mathrm{Si}, \mathrm{Ge})_{3} \mathrm{O}_{9}$, Journal of Ceramic Society of Japan, Vol. 114, pp. 313-317.

Tang, H. Prasad, K. Sanjinès, R.P. Schmid, E. \& Lévy F. (1994). Electrical and optical properties of $\mathrm{TiO}_{2}$ anatase thin films, Journal of Appied Physics, Vol. 75, pp. 2042-2047.

Theis, D. (1977). Wavelength modulated reflectivity spectra of ZnSe and ZnS from 2.5 to $8 \mathrm{eV}$, Physica Status Solidi (B), Vol. 79, pp.125-130.

Vegard, L. (1921). Die Konstitution der Mischkristalle und die Raumerfüllung der Atome, Z. Phys. Vol. 5, pp. 17-26.

Weller, H.. (1991). Quantum sized semiconcuctor particles in solution in modified layers, Berichte der Bunsengeselleschaft Physical Chemistry, Vol. 95, pp. 1361-1365.

Wise, F. W. (2000). Lead salts quantum dots: the limit of strong confinement, Accounts of Chemical Research, Vol. 33, pp. 773-780.

Xue, D. (2009). A template-free solution method based on solid-liquid interface reaction towards dendritic PbSe nanostructures, Modern Physics Letters B, Vol. 23, pp. 3817-3823.

Yang, W. Wan, F. Chen, S. Jiang, C. (2009). Hydrothermal growth and application of ZnO nanowire films with $\mathrm{ZnO}$ and $\mathrm{TiO}_{2}$ buffer layers in dye-sensitized solar cells, Nanoscale Research Letters, Vol. 4, pp. 1486-1492.

Zaban, A. Micic, O. I. Gregg, B. A. \& Nozik, A. J., (1998). Photosensitization of nanoporus $\mathrm{TiO}_{2}$ electrodes with InP quantum dots, Langmuir, Vol. 14, pp. 3153-3156.

Zemel, J. N. Jensen, J. D. \& Schoolar, R. B. (1965). Electrical and optical properties of epitaxial films of PbS, PbSe, PbTe, and SnTe, Physical Review, Vol. 140, pp. A330-A342.

Zhu, G. Su, F. Lv, T. Pan, L. Sun, Z. (2010). Au nanoparticles as interfacial layer for CdS quantum dot-sensitized solar cells, Nanoscale Research Letters, Vol. 5, pp. 1749-1754. 


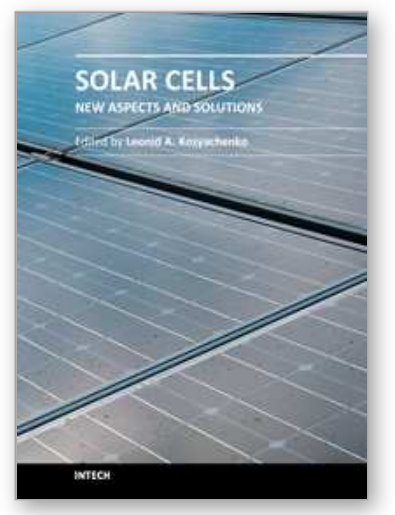

\author{
Solar Cells - New Aspects and Solutions \\ Edited by Prof. Leonid A. Kosyachenko
}

ISBN 978-953-307-761-1

Hard cover, 512 pages

Publisher InTech

Published online 02, November, 2011

Published in print edition November, 2011

The fourth book of the four-volume edition of 'Solar cells' consists chapters that are general in nature and not related specifically to the so-called photovoltaic generations, novel scientific ideas and technical solutions, which has not properly approved. General issues of the efficiency of solar cell and through hydrogen production in photoelectrochemical solar cell are discussed. Considerable attention is paid to the quantum-size effects in solar cells both in general and on specific examples of super-lattices, quantum dots, etc. New materials, such as cuprous oxide as an active material for solar cells, AlSb for use as an absorber layer in $p$-i-n junction solar cells, InGaAsN as a promising material for multi-junction tandem solar cells, InP in solar cells with MIS structures are discussed. Several chapters are devoted to the analysis of both status and perspective of organic photovoltaics such as polymer/fullerene solar cells, poly( $p$-phenylene-vinylene) derivatives, photovoltaic textiles, photovoltaic fibers, etc.

\title{
How to reference
}

In order to correctly reference this scholarly work, feel free to copy and paste the following:

Seishi Abe (2011). One-Step Physical Synthesis of Composite Thin Film, Solar Cells - New Aspects and Solutions, Prof. Leonid A. Kosyachenko (Ed.), ISBN: 978-953-307-761-1, InTech, Available from: http://www.intechopen.com/books/solar-cells-new-aspects-and-solutions/one-step-physical-synthesis-ofcomposite-thin-film

\section{INTECH}

open science | open minds

\section{InTech Europe}

University Campus STeP Ri

Slavka Krautzeka 83/A

51000 Rijeka, Croatia

Phone: +385 (51) 770447

Fax: +385 (51) 686166

www.intechopen.com

\section{InTech China}

Unit 405, Office Block, Hotel Equatorial Shanghai

No.65, Yan An Road (West), Shanghai, 200040, China

中国上海市延安西路65号上海国际贵都大饭店办公楼 405 单元

Phone: +86-21-62489820

Fax: $+86-21-62489821$ 
(C) 2011 The Author(s). Licensee IntechOpen. This is an open access article distributed under the terms of the Creative Commons Attribution 3.0 License, which permits unrestricted use, distribution, and reproduction in any medium, provided the original work is properly cited. 